\title{
EMPRESAS JUNIORES E INTERCÂMBIOS EM GESTÃO: UMA VISÃO CRÍTICA
}

\author{
MANAGEMENT JUNIOR ENTERPRISES AND EXCHANGE EXPERIENCES: CRITICAL VIEW
}

DOI: http://dx.doi.org/10.12712/rpca.v6i4.247

\author{
Jorge Luiz Moraes Doval \\ jlmdoval@gmail.com \\ FADERGS - Faculdade de Desenvolvimento do Rio Grande do Sul - Porto Alegre - RS, Brasil
}

\section{Resumo}

Historicamente, a visão de que o estudante do ensino superior precisa tomar contato com a realidade que estuda em sala de aula, tem assumido o tom de discurso uníssono. Este estudo visa descrever e analisar a forma como duas modalidades de aprendizagem prática se insere no contexto educacional dos cursos de gestão no Brasil: a participação empresas juniores e a realização de intercâmbios internacionais. Buscou-se analisar criticamente as atividades extraclasse oferecidas aos alunos dos cursos de gestão pelas instituições de ensino superior, como forma de proporcionar aos mesmos a chamada 'aprendizagem na prática'. O estudo buscou estudar e descrever como ocorrem, nas instituições de ensino brasileiras, as atividades de participação de estudantes em empresas juniores e em intercâmbios internacionais. Pode-se afirmar que as oportunidades de aprendizagem na prática preconizadas pelas escolas, como é o caso das empresas juniores e dos intercâmbios internacionais, quase sempre se traduzem em modos de inculcação de conhecimentos e maneiras de agir preconizados pela lógica dominante no mercado capitalista. Porém, é fundamental acreditar que é possível uma educação, com intercâmbios e organizações de prática capazes de romper com a lógica meramente mercantil, a alienação e a intolerância, lutando em prol da emancipação humana.

Palavras-chave: Educação. Ensino superior. Gestão. Emancipação. Aprendizagem prática.

\begin{abstract}
Historically, the view that higher education student must make contact with the reality they study in the classroom has assumed the dominance of discourses. This study aims to describe and analyze how two modes of practical learning are offered in the context of educational management courses in Brazil: the participation in junior companies and on international exchanges. We sought to examine critically the extracurricular activities offered to students of management by institutions of higher education as a way to give them a opportunity of 'learning by doing'. The study sought to examine and describe how they occur in Brazilian educational institutions, the activities of student participation in junior companies and in international exchanges. It can be said that learning opportunities in practice advocated by the schools, as is the case of júnior companies and international exchanges, almost always translate into modes of inculcation of knowledge and courses of action recommended by the dominant capitalist market logic. However, it is essential to believe that is possible to have an education with practice exchanges and organizations able to break with the market forces, alienation and intolerance, striving for the sake of human emancipation.
\end{abstract}

Keywords: Education. Higher education. Management. Emancipation. Practical learning. 


\section{Introdução: breve história e contexto da aprendizagem prática na educação brasileira}

Historicamente, a visão de que o estudante do ensino superior precisa tomar contato com a realidade que estuda em sala de aula, tem assumido o tom de discurso uníssono. Especialmente, mas não exclusivamente, nos países chamados emergentes, o discurso em torno da 'aprendizagem prática' ou 'aprendizagem na prática' se tornou uma tendência, haja visto o exemplo do Brasil, onde as modalidades de ensino voltadas à preparação rápida para o mercado de trabalho proliferam nos ciclos de crescimento econômico, visando atender às demandas de profissionais qualificados.

Este estudo visa descrever e analisar a forma como duas modalidades de aprendizagem prática se insere no contexto educacional dos cursos de gestão no Brasil: a participação empresas juniores e a realização de intercâmbios internacionais. Antes, contudo, é importante compreender a trajetória da importância das vivências práticas no contexto educacional brasileiro.

Saviani (2007) aponta para o período da Revolução industrial como um período em que a escola, através do ensino básico, foi a grande responsável pela preparação do trabalhadores para integrarem-se ao processo produtivo industrial de então. Isto ocorreu de tal forma que os principais países logo trataram de organizar seus sistemas nacionais de educação, com a finalidade de preparar os trabalhadores para o trabalho na indústria.

No Brasil, o caráter 'prático' da educação teve seu início marcado pela abolição da escravatura. Segundo Saviani (2007), a partir do momento em que os proprietários de terra não puderam mais contar com a mão de obra escrava, surgiram as primeiras escolas voltadas a formar mão-de-obra para as fazendas. Mais tarde, surgiram os Liceus, voltados à formação profissional de trabalhadores para a agricultura, a arte e o comércio. Já na primeira república, afirma Nosella (1998), foi elaborada uma política educacional que visava, principalmente, democratizar o ensino primário através de uma rede de ensino primário público e gratuito. Porém, o sistema idealizado não seria capaz de atender à demanda por mão-de-obra qualificada e de baixo custo dos empresários da época. Assim, logo os setores econômicos começaram a interferir no modelo educacional proposto, que passou a se adaptar às necessidades de recursos humanos, especialmente dos setores secundário e terciário, conforme Romanelli (1998).

No período pós-segunda guerra, a educação voltada à prática passa a ser abordada a partir das Reformas Capanema, ocorridas entre 1942 e 1946, conforme Saviani (2007). Estas reformas deram origem ao Serviço Nacional de Aprendizagem Industrial (SENAI) e ao Serviço Nacional de Aprendizagem Comercial (SENAC) e às leis orgânicas que regulamentaram o ensino industrial, secundário e comercial. A partir da Reforma Capanema, a educação brasileira passou por uma reestruturação. Criou-se a chamada 'educação regular', que era dividida em dois níveis: educação básica e superior. Com esta nova estrutura, definiu-se o que era esperado da formação de intelectuais e da formação de trabalhadores, levando-se em consideração o que o mercado de trabalho da demandava na época. Estas mudanças propiciaram o surgimento de uma série de cursos profissionalizantes, voltados ao atendimento das demandas crescentes dos setores secundário e terciário. Escolas e cursos profissionalizantes proliferaram, especialmente nos grandes centros urbanos, sem que esta formação profissional pudesse habilitar os estudantes para ingressar no ensino superior.

É perceptível, neste período, a clareza com que ocorre a divisão dos projetos educacionais: o primeiro, voltado às elites, para as quais estava reservada a formação superior nos bancos 
acadêmicos, e; o segundo, ofertado aos trabalhadores, cuja formação estaria restrita aos cursos profissionalizantes. Em outras palavras, pode-se colocar que, àquela época, a ideia da aprendizagem para o fazer estava reservada aos jovens provenientes de camadas sociais proletárias, reforçando a divisão social do trabalho. Enquanto a um grupo restrito de jovens provenientes da elite brasileira estavam destinadas as vagas nas universidades, onde poderiam desenvolver-se intelectualmente participando de toda sorte de atividades acadêmicas, ao grupo majoritário de jovens menos favorecidos social e economicamente resta a possibilidade de aperfeiçoar-se no papel de operário, no que pode ser comparado à determinação de castas, uma vez que, presos a este sistema, estariam fadados à perpetuação do status quo.

É importante ressaltar que, segundo Schwartzman, Bomeny e Costa (2000), a estratégia de delegar ao setor privado os rumos da educação profissionalizante no Brasil não era uma opção do então ministro Capanema e do Ministério da Educação, que defendiam que a educação, em qualquer nível, deveriam ser obrigação do Estado. No entanto, o Ministério do Trabalho interferiu no processo, em favor dos interesses do setor privado, reforçando o que Cunha (2000) chama de caráter corporativista da educação, com o Estado brasileiro representando os interesses da iniciativa privada.

A forma como o sistema educacional passou a se moldar a partir deste período se contrapões ao princípio gramsciano da 'escola única', o que significaria que todos os jovens da sociedade poderia ter acesso a uma educação básica comum (GRAMSCI, 2001). Ao contrário do que propõe Gramsci (2001), o estado brasileiro, naquele momento, entregou à inciativa privada o poder de determinar o que é importante, bem como o que não é importante ser aprendido, estabelecendo assim um sistema educacional voltado à formação profissional a serviço do mercado. Este, ao determinar, organizar e promover a formação dos trabalhadores conforme suas necessidades mercantis, nega-lhes a possibilidade do desenvolvimento intelectual crítico e humanizado. Assim, consolidou-se na construção histórica da educação brasileira o que Gramsci (2001) denomina como a separação entre homo faber e homo sapiens.

Em agosto de 1947, o então 'Estado Novo' estabelece o Estatuto do Ensino Técnico Industrial e Comercial e, em 1957, o Estatuto do Ensino Técnico Agrícola. Em 1961, a primeira Lei de Diretrizes e Bases da Educação Nacional (LDB) abriu a possibilidade de os jovens cursarem o ensino profissionalizante integrado ao ensino médio e deu equivalência aos três diferentes tipos de nível secundário: colegial, magistério e técnico. Na década de 70 , dando suporte ao chamado 'milagre brasileiro', a segunda LDB deu caráter obrigatório ao nível secundário técnico, para atender à demanda por profissionais. Somente em 1996, quando o 'milagre brasileiro' era apenas um remota lembrança, e os cursos secundários de formação geral predominavam sobre os profissionalizantes, que há muito não eram mais capazes de garantir uma vaga no mercado de trabalho, então foi editada uma terceira LDB. Esta LDB extingue a integração entre ensino médio e ensino técnico. Este passa a ser opcional, podendo ser cursado paralelamente ou após o ensino médio (SOTERO, 2011).

A partir dos anos 2000, o Estado brasileiro volta a investir no ensino profissionalizante, revitalizando o ensino técnico a partir da criação e expansão dos Institutos Federais, mas também da criação dos Cursos Superiores de Tecnologia (CSTs), cursos de nível superior enfocados na formação voltada ao mercado de trabalho, e de resultado rápido: os CSTs tem duração média de quatro semestres, a mesma duração de diversos técnicos e profissionalizantes. Porém, é fundamental compreender que este contexto é pano de fundo para um processo maior e mais importante, que há muito determina os rumos não somente 
da formação dos trabalhadores. 0 processo de dominação em que os interesses do capital definem o que é importante e o que não é importante para a educação superior, conforme ocorria com a educação básica no período do Brasil-colônia e com a educação secundária no pós-guerra. Conforme Mészáros (2005), a educação acabou por se transformar em um elemento constituinte do processo de acumulação de capital e de consenso, o que torna possível um sistema de desigualdade.

Neste sentido, é importante ressaltar que o campo da administração não é imune ao processo de dominação do capital sobre a educação. Ao contrário, o processo se reproduz, quem sabe de forma ainda mais clara, visto que trata-se de campo de interesse direto de atuação do capital, uma vez que o discurso da gestão que favorecem sua dominação. Mésáros (2005) aponta que, através deste processo, as classes dominantes impõem uma educação para o trabalho alienante, como forma de manter o homem dominado.

A partir deste contexto geral, este artigo busca debruçar-se sobre os cursos superiores de gestão, entendidos como cursos de administração e correlatos, incluindo os recentes CSTs em gestão. Buscou-se analisar criticamente as atividades extraclasse oferecidas aos alunos dos cursos de gestão pelas instituições de ensino superior, como forma de proporcionar aos mesmos a chamada 'aprendizagem na prática'.

O estudo buscou estudar e descrever como ocorrem, nas instituições de ensino brasileiras, as atividades de participação de estudantes em empresas juniores e em intercâmbios internacionais. As informações foram coletadas junto a páginas de internet de organizações que promovem este tipo de atividade e notícias. Os resultados e análise são apresentados a seguir.

\section{Empresa Junior: treinamento para o fazer em gestão}

Uma das principais oportunidades de atividade extraclasse para alunos de cursos de gestão é a participação em uma empresa júnior. Uma empresa júnior é uma associação civil sem fins lucrativos, em geral criada pelos próprios estudantes, desde que regularmente matriculados em cursos superiores da instituição, com o objetivo de colocar em prática os ensinamentos recebidos em sala de aula através da participação em projetos e prestação de serviços que se enquadrem nas atribuições profissionais da formação que estão recebendo, conforme a Brasil Junior (2012).

Ainda segundo a Brasil Junior (2012), a finalidade de uma empresa júnior consiste em três aspectos, conforme segue:

I - Desenvolver profissionalmente as pessoas que compõem o quadro social por meio da vivência empresarial, realizando projetos e serviços na área de atuação do(s) curso(s) de graduação ao(s) qual(is) a empresa júnior for vinculada;

II - Realizar projetos e/ou serviços preferencialmente para micro e pequenas empresas, e terceiro setor, nacionais, em funcionamento ou em fase de abertura, ou pessoas físicas, visando ao desenvolvimento da sociedade;

III - Fomentar o empreendedorismo de seus associados. (BRASIL JUNIOR, 2012, p. 1-2)

Uma empresa júnior poderá ter outras finalidades, desde que estas não contrariem as três fundamentais. Ainda, conforme documento da Brasil Junior (2012), uma empresa júnior, 
embora independente, com registro e responsabilidade jurídica próprios, somente pode existir se vinculada a uma instituição de ensino superior, através de um atestado oficial da própria instituição, reconhecendo o vínculo com a mesma. Ainda, cabe à instituição de ensino estabelecer uma resolução normativa, regulamentando a relação da mesmo com a empresa júnior, e determinando como se dará o processo de supervisão dos projetos e serviços por professores.

Conforme os dados coletados no processo de pesquisa, a empresa júnior é um tipo de entidade em que mais comumente os alunos dos cursos de gestão se envolvem, sendo atualmente quase tão presente quanto os centros e diretórios acadêmicos. No campo da gestão, existe praticamente uma empresa júnior para cada instituição, quando não houver mais de uma. Existem casos de instituições em que há mais de uma empresa júnior, conforme diferentes especialidades (Recursos Humanos, Marketing, etc.), e outros em que busca-se uma maior integração entre os processos dentro de uma mesma empresa júnior. Um dos fatores que determina a popularidade das empresas juniores é a possibilidade de aprendizagem na prática. 0 segundo fator é a remuneração. Isto é, a empresa júnior se constitui na única entidade que oportuniza aprendizagem na prática em que o aluno, além de não precisar dispender recursos, tem a oportunidade de obter renda.

0 terceiro fator são as oportunidades profissionais decorrentes da atuação em uma empresa júnior. 0 aluno envolvido em uma empresa júnior tem a possibilidade de trabalhar a sua rede de contatos (networking). A participação em projetos, bem como em eventos empresariais, coloca o estudante muitas vezes em contato direto com o meio empresarial. 0 aluno faz contatos e, ao mesmo tempo, tem a oportunidade de demonstrar sua capacidade profissional perante os mesmos. Esta relação não raras vezes resulta na contratação destes estudantes pelas empresas clientes da empresa júnior, ou por empresas participantes da rede de contatos da empresa júnior (apoiadores, palestrantes, patrocinadores, etc.).

É fundamental ressaltar que os três fatores são atrativos para que os estudantes se interessem em integrar a equipe de uma empresa júnior. Também, os três fatores se constituem em formas de o capital determinar o que deve e o que não deve ser aprendido pelos estudantes, reforçando 'na prática' o que já está determinado em grande parte pelos conteúdos apresentados em sala de aula pelos professores. Em outras palavras, trata-se de uma atividade de suporte ao sistema ideológico representado pelo sistema educacional capitalista. Como coloca Mészáros (2005), os processos educacionais estão intimamente relacionados aos processos mais abrangente de reprodução da lógica do capital, não se modificando além dos ajustes necessários ao fortalecimento desta lógica vigente.

Neste sentido, a empresa júnior não se constitui em uma inovação ou transformação, mas em um mecanismo de aprendizagem prática e de ajuste, buscando a conformidade com as exigências da lógica global, a qual se coloca como inalterável, conforme Mészáros (2005). No caso das empresas juniores, trabalha-se com a expectativa de jovens estudantes por uma oportunidade no mercado de trabalho, explora-se o sonho de obter algum destaque no âmbito profissional, e então se propõe ao jovem a adoção da lógica do mercado, da lógica do capital.

Além disto, é importante ressaltar que os membros das empresas juniores se constituem em uma elite dentro dos cursos de gestão. Isto é, não há lugar para todos dentro de uma empresa júnior. Então, mais uma vez, dentro da lógica do mercado, o estudante, que já passou por uma seleção para ingressar no ensino superior, se quiser tomar parte em uma empresa júnior, como forma de obter aprendizagem na prática, terá mais uma vez que submeter-se a um novo processo seletivo, similar ao de qualquer emprego no mercado capitalista. A quantidade de 
estudantes que uma empresa júnior é capaz de absorver é proporcional ao número de clientes. Assim, uma empresa júnior com muitos clientes poderá envolver uma quantidade maior de estudantes, mas nunca esta oportunidade poderá ser usufruída por todos. A partir daí, a prática reforça a ideologia, materializando na formação do estudante de gestão o que Tragtenberg (1979) critica como sendo um conjunto de relações opressivas e desiguais, em que o estudante se depara com uma universidade formadora de quadros para o mercado, uma multiversidade e não uma universidade, onde se ensina o que o aluno se dispõe a pagar, sem compromisso com a construção de saber e de conhecimento.

\section{O Intercâmbio Estudantil: a globalização da multiversidade}

Outro tipo de atividade extraclasse cada vez mais fomentado é a participação dos estudantes de nível superior em intercâmbio no exterior. Proliferam nas instituições de ensino as entidades ou escritórios com a finalidade de incentivar os estudantes a realizarem um intercâmbio. Com menos força e popularidade se comparadas às empresas juniores, as organizações de intercâmbio podem ser independentes das instituições de ensino, ou a elas atreladas. Existem entidades internacionais sediadas dentro das universidades, bem como empresas com sedes neutras (fora dos campus universitários), para atrair estudantes de todas as partes, ou ainda escritórios de intercâmbio, em que as próprias instituições oferecem aos alunos a oportunidade de realizar um intercâmbio fora do país (ROTARY, 2008; AIESEC, 2012; CI, 2012; PUC-RIO, 2012).

Tais organizações voltadas ao intercâmbio, por terem naturezas diferentes, possuem também estruturas diferentes. Enquanto que as entidades formadas por estudantes geralmente são independentes e contam com a dedicação e trabalho voluntário dos mesmos, as empresas voltadas a promover o intercâmbio estudantil são também independentes, mas formadas por profissionais remunerados e capacitados para oferecer o intercâmbio aos estudantes. Ainda, há os escritórios, estes partes integrantes das instituições em que se localizam e onde trabalham funcionários da instituição (ROTARY, 2008; AIESEC, 2012; CI, 2012; PUC-RIO, 2012).

Sob o ponto de vista do público-alvo, as entidades formadas por estudantes (mesmo que sediadas em uma instituição) e as empresas buscam abranger estudantes de todas as instituições, enquanto que os escritórios são voltados estritamente ao atendimento dos estudantes da sua instituição. Também pode haver intercâmbios abertos a estudantes de qualquer área, ou intercâmbios mais específicos, para estudantes de determinados cursos, como por exemplo da área de negócios (ROTARY, 2008; AIESEC, 2012; CI, 2012; PUC-RIO, 2012).

No que tange às modalidades de intercâmbio, existem intercâmbios de prática profissional (os chamados estágios no exterior), os intercâmbios para aprendizado de um idioma estrangeiro, os intercâmbios para cursar um ou mais semestres ou disciplinas e uma instituição estrangeira, ou ainda os intercâmbio mistos, que envolvem uma combinação de mais de uma das modalidades anteriores. Todas as modalidades envolvem atividades turísticas/culturais (ROTARY, 2008; AIESEC, 2012; CI, 2012; PUC-RIO, 2012).

Quanto à duração, os intercâmbios podem variar de quatro semanas (geralmente cursos de idiomas) a dois anos (geralmente estágios no exterior). Há também modalidades de intercâmbio internacional de entidades não relacionadas ao ensino superior, como entidades beneméritas ou religiosas. Como se pode perceber, há uma gama bastante vasta de possibilidades de intercâmbio estudantil no exterior. Porém, embora perceba-se que é um 
anseio de muitos estudantes, trata-se de uma atividade restrita a um grupo menor de pessoas, em razão da barreira idiomática, do custo e da não acessibilidade a todos os estudantes(ROTARY, 2008; AIESEC, 2012; CI, 2012; PUC-RIO, 2012).

A barreira idiomática é um importante fator de restrição à participação do estudantes de um intercâmbio no exterior, visto que nem todos sabem ou dominam um idioma estrangeiro. Aproveitando o fato de o Brasil possuir dimensões continentais, algumas instituições passaram a oferecer também um intercâmbio dentro do país, o que eliminaria esta barreira.

Também o fator custo é um grande restritivo. 0 estudante que deseja realizar intercâmbio, em geral, deve arcar com custos de passaporte, vistos, seguros, passagens aéreas, hospedagem, transporte, alimentação e lazer/turismo no país de destino, bem como os custos de seus estudos na instituição estrangeira. Para se ter uma ideia, um intercâmbio para realizar um curso de idiomas de cinco semanas na Inglaterra custaria em torno de dez mil reais para um estudante. Diante do alto custo, alguns acabam optando por países vizinhos, onde um curso de idiomas de quatro semanas no Chile custaria três mil reais. Outra alternativa para redução de custos são os estágios no exterior. Promovido por algumas organizações, este tipo de intercâmbio apresenta dois aspectos importantes: a possibilidade de hospedagem em alojamentos ou residência de família sem custo e o fato de o estagiário receber mensalmente, por seu trabalho, uma bolsa-auxílio, o que auxilia no custeio do intercâmbio (ROTARY, 2008; AIESEC, 2012; CI, 2012; PUC-RIO, 2012).

Com todas estas possibilidades e diferenças entre os diversos intercâmbios existentes, há um aspecto em comum que une todas as modalidades de intercâmbio: o fato de o intercâmbio estudantil ser um produto, um serviço que, prestado por quem for, precisa ser divulgado e vendido aos estudantes. Existe um mercado do intercâmbio estudantil, o qual é bastante concorrido e pode ser bastante rentável para as organizações que o promovem.

Como qualquer produto, o intercâmbio é apresentado como algo sem problemas. Isto é, somente os aspectos positivos e motivadores da experiência. Porém uma pesquisa na internet é capaz de revelar diversos casos em que estas experiências resultaram em dissabor aos estudantes o que denota a imensa responsabilidade que repousa sobre as organizações que se dispõem a promover o intercâmbio de estudantes: primeiro, a responsabilidade de deslocar estudantes do convívio de suas famílias, amigos e colegas, em um ambiente por eles dominado e de idioma familiar; segundo, a responsabilidade de dar o suporte legal e operacional, para que o estudante tenha toda a documentação, informações e orientações necessárias desde o primeiro momento até seu retorno, e; por fim, o acompanhamento do estudante em seu processo de adaptação e vivencia no país estrangeiro.

0 intercâmbio, em razão do alto custo, ainda é uma realidade distante para a grande maioria dos estudantes de cursos de gestão brasileiros. Porém, trata-se de uma vivência altamente recomendada e preconizada pelo discurso do capital globalizado, um vez que, globalizado, o capital também necessita qualificar suas 'lideranças globais': os gerentes que serão responsáveis pela reprodução da lógica do capital. Assim como as empresas juniores, mas em âmbito internacional, o intercâmbio se traduz no reforço do sistema educacional que continua realizando a divisão social do trabalho: enquanto a 'mão-de-obra', o homo faber de Gramsci (2001) é treinado nos cursos técnicos e cursos superiores de tecnologia, o homo sapiens globalizado é formado em oportunidades restritas de participação em intercâmbios internacionais, sem no entanto se tornar um agente crítico e emancipado do sistema educacional que reproduz a lógica do capital. Ao contrário: cada um em seu papel, homo faber e homo sapiens alinham seus esforços na continuidade do status quo que lutaram para se 
enquadrar.

Assim, pode-se colocar que há muito de alienação nas formas como são conduzidas também as oportunidades de intercâmbio aos estudantes de gestão, contribuindo para a visão Tragtenbergiana de uma universidade transformada em multiversidade, a serviço do mercado capitalista de trabalho (TRAGETENBERG, 1979).

\section{A alienação e as oportunidades de 'aprendizagem na prática'}

É evidente que, quando se fala em divisão social do trabalho nos dias atuais, não se trata de uma referência direta e idêntica à divisão do trabalho descrita nos textos clássicos marxianos. Àquela época, os termos trabalhadores e proletários eram utilizados como sinônimos, pois os trabalhadores assalariados eram predominantemente proletários industriais. No entanto, atualmente existe o que Antunes (1999, p. 196) denomina de "classe-que-vive-do-trabalho", a qual "compreende a totalidade dos assalariados, homens e mulheres que vivem da venda da sua força de trabalho e que são despossuídos dos meios de produção". Esta concepção amplia o conceito marxiano, incorporando a totalidade dos seres sociais que tiram sustento da remuneração de sua força de trabalho, sejam estes trabalhadores produtivos ou improdutivos, configurando uma classe mais heterogênea, complexificada e fragmentada. Considerando esta visão contemporânea da classe trabalhadora, pode-se afirmar que ela é formada, para assumir papéis diferentes, tanto nos cursos técnicos e superiores em tecnologia, quanto nos elitizados cursos acadêmicos de bacharelado das universidades federais.

Considerando a amplificação do conceito proposta por Antunes (1999), a compreensão do processo de alienação marxiano fica mais clara. Marx (1979) destaca dois movimentos fundamentais: a desqualificação do trabalho e a alienação do trabalhador do processo no qual está envolvido. A desqualificação do trabalho está diretamente ligada ao processo de simplificar o trabalho, tirando do trabalhador qualquer possibilidade de criação ou emprego de habilidades específicas e/ou complexas. Este processo de desqualificação é mais visível quanto mais operacional for a atuação do trabalhador, mas está presente em todos os níveis. Já o processo de alienação ocorre a partir da separação do trabalhador do controle e do conteúdo do trabalho. Em um primeiro momento mais restrito aos trabalhadores operacionais, a partir da implementação de ferramentas de tecnologia informacional e da sofisticação dos modelos de gestão, o processo de alienação se agravou também nos níveis gerenciais, cada vez menos pensantes e menos empoderados nas organizações.

Motta (2003) coloca que, no âmbito da gestão, domina a noção da racionalidade como sinônimo de racionalidade instrumental. Ramos $(1983 ; 1989)$ critica a ingenuidade do campo administrativo ao considerar a racionalidade instrumental como sendo o modo dominante de pensamento no contexto da administração. Ambos concordam em torno da existência de uma outra racionalidade, chamada por Ramos $(1983 ; 1989)$ de racionalidade substantiva e por Motta (2003) de uma racionalidade relativa a valores. Esta racionalidade, existente, porém amplamente negada ou subsumida no contexto do pensamento em gestão, explica em grande parte a existência das relações de dominação existentes e que se refletem no contexto educacional dos cursos do campo da gestão.

O processo de dominação do mundo do trabalho pela lógica do capital conseguiu, ao longo dos anos, dobrar a espinha do sistema educacional, que curva-se aos interesses do mercado e torna-se, ele também, um mercado educacional, em que as instituições de ensino não possuem poder para contrapor as imposições do setor empresarial, que demanda como devem os 
'produtos' gerados pelo mercado educacional (os profissionais), doravante referidos como profissionais-produtos. Cada vez mais padronizados segundo uma lógica de mercado, tais profissionais-produtos tem seus 'processo produtivos' (currículos e abordagens de ensinoaprendizagem) ditados pelo 'mercado consumidor' (o mercado capitalista de trabalho). Este mercado vem determinando, em todos os patamares, como deve ser o processo 'educacional' que servirá aos seus objetivos: determina a atuação governamental, influenciando diretamente na regulamentação e normatização da educação no país, mas também na estruturação das instituições públicas e privadas (especialmente estas últimas), dos currículos, e ainda na formação e atuação dos professores, que a cada dia são mais pressionados por resultados (leia-se volume de matrículas e rematrículas, traduzidos em receita para as instituições), como em qualquer empresa tradicional. Esta reificação do mercado traduz o que Mészáros (2005) aponta como um conjunto de princípios reprodutivos orientadores dominantes na própria sociedade, que estão adequados à manutenção da dominação da lógica do capital sobre qualquer outra possibilidade diversa, à qual os indivíduos encontram-se submetidos e devem, através da educação, ser induzidos a uma aceitação ativa (ou mais ou menos resignada).

Assim, preconiza-se que, para uma aprendizagem 'na prática' de como se portar diante do mercado de trabalho e obter sua aceitação, o chamado 'lugar ao sol', seja ele local ou global, são inculcados nos indivíduos, a partir da formação superior, toda sorte de modelos de gestão e teorias organizacionais que possam reforçar de forma científica aquilo que já está apreendido a partir de conteúdos ditos e dos não ditos do seu dia-a-dia. Desta forma, a participação dos estudantes de cursos de gestão em atividades como uma empresa júnior ou o intercâmbio internacional contribuem sobremaneira para o que Althusser (1980) aponta como a materialização da ideologia dominante por meio dos aparelhos ideológicos do Estado, dentre os quais a Escola é o mais importante, especialmente porque se constitui na forma mais acabada de reprodução das relações capitalistas. Para isto, ao assumir a responsabilidade de formação dos indivíduos de todas as classes sociais, lhes 'ensina' saberes práticos da ideologia dominante.

Sob este ponto de vista, pode-se afirmar que as oportunidades de aprendizagem na prática preconizadas pelas escolas, como é o caso das empresas juniores e dos intercâmbios internacionais, quase sempre se traduzem em modos de inculcação de conhecimentos e maneiras de agir. Mesmo assim, não se deve negar a possibilidade deste tipo da aprendizagem por meio da experiência vir a ser transformadora, seja por ato de emancipação do indivíduo, seja por meio de iniciativas libertadoras.

\section{Considerações finais: em busca da experiência transformadora}

Embora seja um pouco decepcionante perceber que atividades tão preconizadas como a participação em empresas juniores, ou a realização de um intercâmbio, invariavelmente deverão resultar no reforço - e não na quebra - da lógica do capital e que, de uma forma geral, a experiência de formação superior em cursos de gestão é mantenedora de um status quo em que a alienação do indivíduo em torno de uma ideologia dominante é fator preponderante, não seria correto negar a possibilidade de experiências práticas, construídas sob outras óticas e lógicas, serem transformadoras e emancipadoras do indivíduo. Seria negar o que Mészáros (2005) classifica como uma mudança qualitativa, e se conformar com a ideia fatalista de que não há alternativas à lógica da globalização capitalista.

É fundamental acreditar que é possível uma educação, com intercâmbios e organizações de prática capazes de romper com o que Mészáros (2005) chama de lógica meramente mercantil, 
a alienação e a intolerância, lutando em prol da emancipação humana.

Em Educação como Prática da Liberdade, Freire (1967) destaca a importância de estar no mundo e com o mundo. Isto é, a relevância essencial do existir individual e, a partir deste existir transcender, discernir e dialogar. Não é possível fazer isto sem o existir. É fundamental o homem conhecer-se, saber onde está, de onde vem, quem ele é. Assim, o indivíduo adquire experiência e integra-se ao contexto em que está inserido. Com isto, é lançado no domínio da história e da cultura, aprendendo a ajustar-se à realidade sem acomodar-se, mas vislumbrando maneiras de transformá-la, não para seu bem exclusivo, mas para benefício geral, visto que, ao conhecer-se, torna-se capaz de reconhecer-se no outro, e de posicionar-se como parte integrante de uma coletividade maior. Isto é, o indivíduo livre e emancipado pela educação é capaz da solidariedade, da coletividade.

O exemplo da Universidad de las Madres de Plaza de Mayo (SILVA, 2008), demonstra que é possível organizar-se em torno de uma prática emancipadora, diversa das multiversidades detentoras do que Tragtenberg (1990, p. 11) denomina como uma "autonomia capenga" e compostas pelo "complô das belas almas, recheadas de títulos acadêmicos, de doutorismo substituindo o bacharelismo, de uma nova pedantocracia, da produção de um saber a serviço do poder, seja ele de que espécie for."

Motta (2003) coloca que uma educação participativa tende a favorecer a aquisição de algo que ele refere como habilidades de valor, o que irá se refletir na capacidade de participar, mas também no desejo em participar, visto que pessoas educadas em contextos autoritários podem demonstrar desinteresse na participação, já que implicam no aumento importante do grau de desgaste em emocional ou mesmo físico relacionado a este envolvimento.

A possibilidade de ter uma participação efetiva da sociedade (vista não somente como as 'lideranças empresariais') e, especialmente, dos indivíduos que estudam nas instituições, seria um caminho interessante para a construção de uma educação transformadora. Silva (2008) descreve a Universidad de las Madres de Plaza de Mayo como uma organização onde a horizontalidade permite a criação de processos educacionais libertadores, produtores de indivíduos livres, conscientes e críticos. O próprio Tragtenberg (1979) defende a possibilidade da prática autogestionária:

A autogestão pedagógica teria o mérito de devolver à universidade um sentido de existência, qual seja: a definição de um aprendizado fundado numa motivação participativa e não no decorar determinados "clichês", repetidos semestralmente nas provas que nada provam, nos exames que nada examinam, mesmo porque o aluno sai da universidade com a sensação de estar mais velho, com um dado a mais: o diploma acreditativo que em si perde valor na medida em que perde sua raridade".(TRAGTENBERG, 1979, p.16)

Enxergar as possibilidades significa, por fim, visualizar saídas para a aparente e falsa inexorabilidade do processo de dominação do capital sobre a educação em cursos de gestão. Significa ver que há organizações para além dos modelos de gestão preconizados pelo capital. Significa entender que é possível ter aprendizagem na prática a partir do conhecimento e do desenvolvimento de práticas emancipadoras e humanizadoras. Cabe aos indivíduos buscar o desenvolvimento da consciência crítica capaz de embasar a construção destas práticas transformadoras do contexto educacional brasileiro. 


\section{Referências}

AIESEC. Site da organização estudantil de intercâmbio AIESEC. Acesso disponível em < http://www.aiesec.org/> em 19 de novembro de 2012.

ALTHUSSER, L. Ideologia e Aparelhos Ideológicos do Estado. Lisboa, Portugal. Editorial Presença/Martins Fontes. 1980.

ANTUNES, Ricardo. Os sentidos do trabalho: ensaio sobre a afirmação e a negação do trabalho. São Paulo: Boitempo Editorial, 1999.

BRASIL JUNIOR. Confederação Brasileira de Empresas Juniores. Conceito Nacional de Empresa Junior. 2012. Acesso disponível em < http://brasiljunior.org.br/> em 16 de novembro de 2012.

CI. Central de Intercâmbio. Site comercial da empresa Central de Intercâmbio. Disponível em Acesso disponível em < http://www.ci.com.br/> em 20 de novembro de 2012.

CUNHA, L. A. 0 ensino profissional na irradiação do industrialismo. São Paulo: UNESP, Brasília, DF: Flasco, 2000.

FREIRE, P. Educação como prática da liberdade. Rio de Janeiro: Paz e Terra, 1967

GRAMSCI, Antonio. The Formation of Intellectuals. Norton Anthology of Theory and. Criticism. Ed. Vincent Leitch. New York: Norton, 2001.

MÉSZÁROS, István. A educação para além do capital. São Paulo: Boitempo, 2005.

NOSELLA, Paolo. A escola brasileira no final do século: Um balanço - In: FRIGOTTO, Gaudêncio (org.). Educação e crise do trabalho: Perspectivas de final de século. Petrópolis, RJ: Vozes, 1998.

MOTTA, Fernando C. Prestes. Administração e participação: reflexões para a educação. Educ. Pesqui., São Paulo, v. 29, n. 2, Dec. 2003.

PUC-RIO. Pontifícia Universidade Católica do Rio de Janeiro. Site da instituição. Acesso disponível em <http://www.puc-rio.br/> em 19 de novembro de 2012.

RAMOS, A. Administração e contexto brasileiro: esboço de uma teoria geral da administração. Rio de Janeiro: FGV, 1983.

RAMOS, A. A nova ciência das organizações - uma reconceituação da riqueza das nações. 2. ed., Rio de Janeiro: FGV, 1989.

ROMANELli, Otaíza de Oliveira. História da Educação no Brasil. 16 ${ }^{a}$ Ed. Petrópolis, RJ: Vozes, 1998.

ROTARY. Rotary International. Manual do Intercâmbio de Jovens. 2008. Acesso disponível em < http://www.rotary.org/> em 20 de novembro de 2012.

SAVIANI, Dermeval. História das idéias pedagógicas no Brasil. Campinas, SP: Autores Associados, 2007.

SCHWARTZMAN, S., H.M.B. BOMENY, and V.M.R. COSTA. Tempos de capanema. 2. ed. 
Numero de. São Paulo, Rio de Janeiro: Paz e Terra; Editora da Fundação Getúlio Vargas, 2000.

SILVA, Joysinett Moraes. Práticas organizacionais em escolas de movimentos sociais. Tese de Doutorado apresentada ao PPGA/UFRGS em março de 2008.

SOTERO, E. C. . Reformas no ensino técnico brasileiro: diferentes concepções e modelos de desenvolvimento para a nação.. In: 35을 Encontro Anual da Anpocs, 2011, Caxambú. Anais do 35을 Encontro Anual da Anpocs, de 24 a 28 de outubro de 2011, em Caxambu/MG, 2011. v. 1. p. $1-22$.

TRAGTENBERG, M. A delinqüência acadêmica: o poder sem saber e o saber sem poder. São Paulo: Rumo Gráfica, 1979.

TRAgtenberg, M. Sobre Educação, Política e Sindicalismo. 2. ed., São Paulo: Cortez Editora/Autores Associados, 1990. 